\title{
Discussion on "Proposed Code of Ethics", at Niagara Falls, N. Y., June 28, 1907
}

Schuyler S. Wheeler: The report I have to present represents the work during the last year of a special committee of three consisting of Charles P. Steinmetz, Harold W. Buck, and myself. The committee was appointed at the last annual convention to take up questions that were raised by the presidential address of last year on the subject of engineering honor. This address brought up the subject of ethics and the professional conduct of engineers. A committee was appointed to look into the matter and see if any kind of a code should be prepared.

I am happy to say that our committee has been most harmonious in all of its conclusions. We have not disagreed over a single feature in the entire report. Another matter that I want to mention is that we have no idea that the present report is right throughout. We look upon it as a mere starting point, and we think that it will be very useful to us all, because it will at least furnish us what engineers call a datum line; and taking this we can go on with it and make improvements, and constantly make our list of principles better as time goes on.

The report was presented to the Board of Directors and accepted and ordered to be printed and sent to all of the members of the Institute in order that they might examine it so as to pass upon it intelligently at this convention.

William McClellan: I think that all of us at times have found the need of some such code as this. Questions come to us of more or less importance concerning which we should like to know just how other men of our profession would think. I believe that if this proposed code is examined carefully, it will be found that we are not limited or constrained by minor details but are given broad principles which may be interpreted according to the facts of the particular case. No doubt some of us would write such a code differently in details and would, perhaps, desire to have certain changes. This, however, should not prevent it from receiving favorable consideration from every member of the Institute.

Henry G. Stott: I think that the committee has done very admirable work in bringing together for the first time a code of ethics for the American Institute of Electrical Engineers, but there are some individual rules with which I do not agree at all. Take, for example, No. 11, which reads as follows:

11. Operating engineers should consider themselves responsible for defects in apparatus or dangerous conditions of operation, should bring the same to the attention of their employers and urge remedial action. If the causes of the danger are not removed they should withdraw.

Now, that is purely academic. Is there in this room any operating engineer who would do a thing like that? I for one would not, because the conditions may be such that it is abso- 
lutely impossible for the employer with all the resources at his command to overcome these defects. The operating engineer would not be doing his duty if he should withdraw; his duty is to stand by the apparatus and his employer until such time as the defects can be remedied.

I also take exception to the following rule, No. 12, which states among other things that,

12. It should therefore be clearly understood at the outset just what the extent or the limitations of responsibility of the engineer are to be.

Personally, I would not have a man work for me who started out with such a conception of his duties. I would want a man who would agree to accept responsibilities beyond what I ask him to accept at first, and I think every employer would feel the same way. I would not want to have it understood that an engineer is responsible up to that particular bolt or this particular plate and not any further, and the next man who comes along is responsible for what follows. If there is something wrong, is it not our duty, as engineers, to report it?

I think the rules are altogether too specific, and I would like to see them recast so as to make them broader.

Rule 20, states that designs, data, records, and notes obtained by an engineer employed on salary, are his employers' property; while the same matter in the case of a consulting electrical engineer paid by fee or by commission, are the property of the consulting engineer. I do not see the fine point in that distinction.

Then, again, Rule 26 as follows:

26. In giving expert testimony before judicial bodies, the electrical engineer should confine himself to brief and clear statements on engineering or historical facts. He should not give personal opinions without so expressly stating, and should avoid pleading on one side or the other.

The man who is on the stand giving expert testimony does not get a chance to express himself. It is entirely up to the lawyers as to what the man says. He usually says "Yes" or "No", and he does not get a chance to express his opinion.

Rule 32 provides:

32. He should not take a position left by another electrical engineer without satisfying himself that the former has left it voluntarily, or for proper reasons.

That is a perfectly correct attitude, but it may be there would be such a condition as that a man has been ill, or has absented himself from duty for some reason or other, and he cannot be reached. Under these conditions should we say that the employer has not the right to ask some one else to take up his duties if the man has, absented himself? I think not.

H. W. Buck: Mr. Stott thinks that some of the rules are too specific. It was with the full knowledge of the committee that some of the rules were made very specific, and it was the belief of the committee that by only making them so radical 
and specific could general criticism be brought forth, by attracting attention to the various questions at issue. The committee realizes that many changes will have to be made, but I personally feel that if it is the sentiment of the meeting to have such a code at, all, the best way is to recommend its adoption as offered by the committee. If it is allowed to lapse and further criticism is called for by correspondence or vote, I think it will simply result in the gradual disintegration of the proposed code through excessive criticism.

Charles F. Scott: I think that we should accept the report and have it published to the membership, with the strong endorsement it has in the names of the committee; that our Board of Directors should be asked by this meeting to continue a committee of this kind for consideration of suggestions which may be made to the committee and that the committee be asked to present a redraft of the report.

At the beginning of the next session, on Friday morning, June 28, 1907, President Sheldon said: The Chair will entertain a motion to the effect that the report of the Code of Ethics Committee be referred to the Board of Directors for their consideration.

[The motion was made by Henry G. Stott, seconded by Lewis B. Stillwell, and adopted by the convention.]

* For revised Proposed Code of Ethics as considered by the Board of Directors and submitted to the membership for suggestions, see Appendix, page 1789. 